\title{
Koyun ve Keçilerde Doğumun İndüksiyonu Sonuçlarının Değerlendirilmesi
}

\author{
E. Sinem ÖZDEMiR SALCI ${ }^{1 *}$, Kamil SEYREK INTAŞ ${ }^{1}$
}

\author{
${ }^{1}$ Uludağ Üniversitesi, Veteriner Fakültesi, Doğum ve Jinekoloji Anabilim Dalı, Görükle Kampüsü, Bursa, Türkiye
}

Geliș Tarihi: 11.05.2018

Kabul Tarihi: 13.06.2018

\begin{abstract}
Özet: Bu çalışmada, koyun ve keçilerde uygulanan rutin medikal doğum indüksiyon yöntemlerinin klinik sonuçlarının aktarılması amaçlanmıştır. Çalışma materyalini anamnez ve klinik muayene sonuçlarına göre gebeliğin son döneminde tespit edilmiş problemler sonucu doğum indüksiyonu uygulanan farklı ırk, yaş ve gebelik sürelerindeki 11 koyun ve 6 keçi oluşturdu. Koyunlarda doğumun indüksiyonu amacıyla $16 \mathrm{mg}$ deksametazon, keçilerde ise $10 \mathrm{mg}$ dinoprost uygulandı. Doğumların indüksiyonu sonrası koyunlarda $36.1 \pm 10.32$ saat, keçilerde ise $34.41 \pm 2.95$ saat sonra doğumlar gerçekleşti. Koyunların 10'u normal doğum yaptı ve sadece 1 koyun güç doğuma bağlı sezaryen operasyonuna alındı. Keçilerin tümünde vaginal doğum şekillendi, ancak sadece 1 keçide fötal malpozisyon nedenli doğuma elle müdahale edildi ve bu keçide postpartum metritis şekillendi. Koyunlardan 17 canlı (10 erkek ve 7 dişi) 1 ölü (dişi) kuzu, keçilerden ise 6 erkek, 3 dişi olmak üzere 9 adet canlı oğlak elde edildi. Kuzuların vücut sıcaklığı $36.67 \pm 0.72^{\circ} \mathrm{C}$; vücut ağırlıkları $2.90 \pm 0.50 \mathrm{~kg}$; oğlakların ise beden ısıları $36.83 \pm 0.87^{\circ} \mathrm{C}$; vücut ağırlıkları $2.84 \pm 0.58 \mathrm{~kg}$ 'dı. Sonuç olarak, koyun ve keçilerde uygulanan rutin doğum indüksiyonları annenin genel durumunun iyi olduğu ve olgunun acil olmadığı durumlarda tercih edilebilir. Ancak ileri derecede sağlık problemi bulunan koyun ve keçilerde sezaryen operasyonuna başvurulması daha uygun bir yaklaşım olacaktır.
\end{abstract}

Anahtar Kelimeler: Deksametazon, Doğum indüksiyonu, Keçi, Koyun, PGF2a.

\section{Evaluation of Induction of Parturition Results in Sheep and Goats}

Abstract: In this study, it is aimed to convey the clinical outcomes of routine medical methods of induction of parturition applied in sheep and goats. The material of the study consisted of 11 sheep and 6 goats with different breed and age and gestation period by which the parturitions induced according to the anamnesis and clinical examination results at the late gestation period. In sheep, a total dose of $16 \mathrm{mg}$ of dexamethasone was administered for induction of parturition whereas $10 \mathrm{mg}$ of dinoprost was administered to the goats. The duration from induction to parturition averaged $36.1 \pm 10.32$ hours in sheep and $34.41 \pm 2.95$ hours in goats. The parturitions in 10 sheep occurred normally however one sheep underwent a cesarean section. Vaginal delivery was achieved in all of the goats, but only a case of fetal malposition was manually intervened, and resulted postpartum metritis. There were 17 live (10 males and 7 female) and 1 dead (female) lambs from the sheep and 9 live yeanlings ( 6 males and 3 female) from goats. Mean body temperature of the lambs was $36,67 \pm 0,72{ }^{\circ} \mathrm{C}$; body weights $2.90 \pm 0.50 \mathrm{~kg}$; body temperatures of the yeanlings were $36.83 \pm 0.87^{\circ} \mathrm{C}$; body weights were $2.84 \pm 0.58 \mathrm{~kg}$. As a result, routine induction of parturition in sheep and goats may be preferred when the general health status of the mother is good and the case is not urgent. However, it would be more appropriate to prefer cesarean operation in sheep and goats having health problems.

Keywords: Dexamethasone, Goat, Induction of parturition, Sheep, PGF2 $\alpha$.

\section{Giriş}

Obstetrik uygulamaların başlıca amaçlarından biri doğum sırasında annenin maruz kaldığı travmayı en aza indirerek, mevcut gebeliğin sağıklı bir yavru doğumu ile sonuçlanmasını sağlamaktır. Acil sezaryen şartlarının oluşmadığı, ancak anne veya yavru açısından gebeliğin sonlanmasının gerekli olduğu durumlarda doğumun mekanik ya da medikal olarak başlatılması gerekebilir (Gelegen, 2013; Karademir, 2005). Fötal membranların hidropsu, prepubic tendo rupturu (Purohit, 2010; Purohit, 2012), travma, gebelik toksemisi gibi metabolik rahatsızlıklar, respiratorik distres (Purohit, 2012; Zoller ve ark., 2015) ve uzayan gebeliklerde (Purohit, 2012) doğum indüksiyonu endikasyon bulur. Özellikle birden fazla yavruya sahip gebe koyunlar (Zoller ve ark., 2015), obez koyun ve keçiler (Lima ve ark., 2012) gebeliğin ilerleyen döneminde metabolik bozukluklara daha eğilimli olurlar (Lima ve ark., 2012; Zoller ve ark., 2015). Travmatik yaralanma, respiratorik distres ve gebelik toksemisi gibi hastalıklarda doğum indüksiyonu küçük ruminantlar için hayat kurtarıcı bir tedavi seçeneğidir (Zoller ve ark., 2015).

Progesteron üretim kaynağı türler arasında ve aynı tür içerisinde gebelik dönemine göre değişkenlik gösterir. Bu nedenle koyun ve keçilerde doğumun indüksiyonu için farklı yöntemler tercih edilmektedir (Purohit ve ark., 2012). Progesteron, 
keçilerde gebelik süresi boyunca luteal yapıdan, koyunlarda ise gebeliğin ilk 1/3'ünden sonra plasentadan salgılandığı için keçilerde prostaglandin ve analogları ile doğum her dönem uyarılabilirken, koyunlarda ise tek başına prostaglandinler kullanılarak doğumu uyarmak yeterli olmaz (Batista ve ark., 2011; Kastelic ve ark., 1996; Purohit, 2010; Purohit ve ark., 2012; Sanchez-Aparicio ve ark., 2009). Koyun ve keçilerin doğum indüksiyonunda fötal kortizole benzer bir etki göstererek doğumun başlamasını sağlayan kortikosteroidler, miyometriyal kontraksiyonları uyaran prostaglandin F2 alfa (PGF2 $\alpha$ ) ve servikal dilatasyonu sağlayan prostaglandin E1 analogları, progesteron reseptörlerine bağlanarak etki gösteren progesteron reseptör blokörleri ve $3 ß$-hidroksi steroid dehidrojenaz enzim inhibitörleri gibi çeşitli medikal preparatların kullanıldığı bildirilmektedir (Currie ve Thorburn, 1973; Ingoldby ve Jackson, 2001; Salci ve ark., 2018).

Sunulan bu çalışmada koyun ve keçilerde doğuma yakın dönemde karşılaşılmış patolojik durumlar nedeniyle uygulanmış olan rutin doğum indüksiyon yöntemlerinin klinik sonuçlarının veteriner pratik yapan meslektaşlarımızla paylaşılması amaçlanmıştır.

\section{Materyal ve Metot}

Bu çalışmanın materyalini Bursa ili Osmangazi ilçesindeki bir sürüde bulunan, planlanmış bir proje çalışması (Proje No: OUAP-MPMYO 2013/44) esnasında abdominal travma ya da genel durum bozukluğu, halsizlik şikayetleri ile tarafımıza sunulmuş ve yapılan muayeneler sonucu doğum indüksiyonu kararlaştırılmış 4'ü Merinos, 7'si Kıvırcık ırkı; $3.04 \pm 0.56$ yaşında; $61.63 \pm 8.01 \mathrm{~kg} ; 144 \pm 2.92$ gebelik gününde toplam 11 adet, koyun ve Saanen ırkı; $3.16 \pm 1.32$ yaşında; $60.16 \pm 13.52 \mathrm{~kg} ; 145.2 \pm 1.41$ gebelik gününde 6 keçi oluşturdu (Tablo 1).

Anamnezde tüm olguların doğuma yakın dönemde olduğu görüldü ve yapılan rutin klinik (beden ISISI, pulzasyon, respirasyon, mukozal membran rengi, kapillar dolum zamanı, lokal lenf yumrularının büyüklüğü ve rumen hareketlerinin tayini) ve vaginal muayene (serviksin açıklığı ve vulvada ödem varlığı) sonucunda doğum indüksiyonu endikasyonu belirlendi. Koyun ve keçilerin ultrasonografik muayenesinde, yavru canlılığı, fötal kalp atımı ve yavru hareketleri izlendi (Ingoldby ve Jackson, 2001). Laboratuar muayenesi olarak, vena jugularis'ten alınan kan numunesinde total lökosit sayımı ve hematokrit ölçümü ile birlikte idrarın strip muayenesi yapıldı. Bu muayenelerin ardından, bireysel yetiştiricinin de kabul etmesiyle destekleyici tedavi (parenteral sıvı elektrolit infüzyonu, oral propilen glikol vb.) başlanarak doğumlar uyarıldı.

Doğum indüksiyonu amacıyla keçilerde PGF2 $\alpha$ analoğu (dinoprost) (Dinolytic ${ }^{\circ}$ Pfizer, İstanbul) koyunlarda ise deksametazon sodyum fosfat (Devamed ${ }^{\oplus}$, Topkim, İstanbul) vücut ağırlığına göre doze edilerek kullanıldı. Uygulamaya ait detaylar Tablo 1'de verildi. Koyunlarda 16 mg deksametazon ya tek doz (140. gebelik gününden sonra) ya da 12 saat aralıklar ile tekrarlayan dozda (140. gebelik gününden önce), keçilerde ise tek doz $10 \mathrm{mg}$ dinoprost kullanıldı. Doğuma kadarki süreçte tüm koyun ve keçiler ayrı bir boksta gözlem altına alındı. Doğumun olduğu anki koyun ve keçilerin genel muayeneleri ve doğumlarının şekli kayıt edildi. Indüksiyon uygulanması ile doğum şekilleninceye kadarki geçen süre belirlenerek kaydedildi. Doğan yavru sayısı, yavruların cinsiyeti, vücut ağırlıkları, canlılık durumları ile yavruların genel muayene bulguları not edildi.

Elde edilen tüm laboratuvar ve parametrik klinik bulguların ortalama değer ve standart sapmaları hesaplandı. İstatistiki farkın anlamlıı̆̆ IBM SPSS 23.0 istatistiki paket programında t- testi ile analiz edildi. İstatistiksel olarak koyun ve keçilerin doğum indüksiyonu ile doğumun gerçekleştiği süre arasındaki anlamlılık t-testi ile koyun ve keçilerden doğan yavruların ağırlıkları ve vücut sıcaklıkları arasındaki fark yine t-testi ile gerçekleştirildi. Anlamlılık değeri $\mathrm{P}<0.05$ olarak belirlendi.

\section{Bulgular}

Çalışmada doğumu uyarılan koyunların gebelikleri $144 \pm 2.92$ gün, keçilerin $145.2 \pm 1.41$ gün idi. Olguların kliniğe getirildiklerindeki kalp frekansı $164 \pm 11$ /dakika, solunum sayısı $48 \pm 16$ /dakika ve beden Isıları ise $38.6 \pm 0.6^{\circ} \mathrm{C}$ idi. Laboratuar analizlerinde, total lökosit değerleri 10.06 \pm 2.8 $10^{9} / \mathrm{L}$, hematokrit değeri $\% 33.3 \pm 6.7$, kan glukoz değeri de $57.64 \pm 19.74 \mathrm{mg} / \mathrm{dl}$ arasında değişmekteydi. İdrardaki keton değerleri ise $2.43 \pm 0.49$ olarak saptandı. Anamnez, klinik ve laboratuar sonuçlarına göre 2 keçi ve 1 koyunda respiratuar distres, 2 keçi ve 7 koyunda subklinik gebelik toksemisi, 1 keçi ve 1 koyunda gebelik toksemisi, 1 koyunda gebelik toksemisi ve respiratuar distres, 1 keçi ve 1 koyunda da abdominal travma mevcut idi.

Yapılan indüksiyon uygulaması sonrası koyunlarda $36.1 \pm 10.32$ saat, keçilerde ise 
34.41 2.95 saat sonra doğumlar gerçekleşti. Koyunların 10 'u normal doğum yaptı ve sadece 1 'i güç doğum nedenli sezaryen operasyonuna alındı. Keçilerin tümünde vaginal doğum şekillendi, ancak sadece 1 keçide (olgu 7) fötal malpozisyon nedenli doğuma elle müdahale edilmek zorunda kalındı. Yine bu keçide (olgu 7) postpartum metritis şekillendi. Doğum indüksiyonu uygulanan koyun ve keçilerden dünyaya gelen yavrulara ilişkin bilgiler Tablo 1'de verildi. İstatistiksel olarak, koyun ve keçilerin doğum indüksiyonu ile doğumun gerçekleştiği süre arasında anlamlı bir fark bulunmadı $(P=0.706)$. Koyun ve keçilerden doğan yavruların ağırlıkları $(P=0.662)$ ve vücut sıcaklıkları $(P=0.631)$ arasında anlamlı bir fark belirlenmedi.

Tablo 1. Olgular ve doğan yavrulara ait tüm bilgi ve bulgular.

\begin{tabular}{|c|c|c|c|c|c|c|c|c|c|}
\hline $\begin{array}{l}\text { Olgu } \\
\text { no }\end{array}$ & $\begin{array}{l}\text { İndüksiyon } \\
\text { nedeni }\end{array}$ & $\begin{array}{l}\text { Kaçıncı } \\
\text { gebelik }\end{array}$ & $\begin{array}{l}\text { Gebelik } \\
\text { günü }\end{array}$ & $\begin{array}{c}\text { İndüksiyon } \\
\text { yöntemi ve dozu }\end{array}$ & $\begin{array}{c}\text { İndüksiyo } \\
\text { n doğum } \\
\text { arası süre } \\
\text { (saat) }\end{array}$ & $\begin{array}{l}\text { Doğan } \\
\text { yavru } \\
\text { sayısı }\end{array}$ & $\begin{array}{l}\text { Doğan } \\
\text { yavruların } \\
\text { cinsiyeti }\end{array}$ & $\begin{array}{l}\text { Yavruların } \\
\text { kilosu (gr) }\end{array}$ & $\begin{array}{l}\text { Yavruların } \\
\text { doğum } \\
\text { sonrası } \\
\text { beden ISISI } \\
\left({ }^{\circ} \mathrm{C}\right)\end{array}$ \\
\hline 1 & $\begin{array}{l}\text { Abdominal } \\
\text { travma }\end{array}$ & 3 & 146 & 10 mg Dinoprost & 33 & 1 & $\delta$ & 3.200 & 38.1 \\
\hline 2 & $\begin{array}{c}\text { Abdominal } \\
\text { travma }\end{array}$ & 2. & 148 & $\begin{array}{c}16 \mathrm{mg} \\
\text { Deksametazon }\end{array}$ & 20 & 2 & $\hat{\sigma} ; \hat{\sigma}$ & $\begin{array}{c}3.300 \\
3.700 \\
\end{array}$ & $38.0 ; 37.3$ \\
\hline 3 & $\begin{array}{l}\text { Respiratorik } \\
\text { distress }\end{array}$ & 3. & 139 & $\begin{array}{c}16 \mathrm{mg} \\
\text { Deksametazon } \\
\text { tekrarlı }\end{array}$ & 34 & 1 & $\hat{\sigma}$ & 3.100 & 37.2 \\
\hline 4 & $\begin{array}{l}\text { Respiratorik } \\
\text { distress }\end{array}$ & 2. & 144 & 10 mg Dinoprost & 33,5 & 2 & $+; \sigma^{\lambda}$ & $\begin{array}{c}2.380 \\
2.400\end{array}$ & $36.1 ; 36.3$ \\
\hline 5 & $\begin{array}{l}\text { Respiratorik } \\
\text { distress }\end{array}$ & 2. & 144 & 10 mg Dinoprost & 35 & 1 & q & 2.150 & 35.1 \\
\hline 6 & $\begin{array}{l}\text { Subklinik } \\
\text { gebelik } \\
\text { toksemisi }\end{array}$ & 1. & Son hafta & $10 \mathrm{mg}$ Dinoprost & 31,5 & 1 & $\sigma^{\pi}$ & 3.900 & 37.3 \\
\hline 7 & $\begin{array}{l}\text { Subklinik } \\
\text { gebelik } \\
\text { toksemisi }\end{array}$ & 3. & 147 & 10 mg Dinoprost & 40 & 3 & $\begin{array}{l}\hat{\partial} ; \hat{o} ; \\
\quad q\end{array}$ & $\begin{array}{l}2.700 \\
2.900 \\
2.500\end{array}$ & $\begin{array}{c}37.4 ; 37.1 \\
36.9\end{array}$ \\
\hline 8 & $\begin{array}{l}\text { Subklinik } \\
\text { gebelik } \\
\text { toksemisi }\end{array}$ & 1. & $\begin{array}{l}\text { Son 1-2 } \\
\text { gün }\end{array}$ & $\begin{array}{c}16 \mathrm{mg} \\
\text { Deksametazon }\end{array}$ & 21 & 2 & q; $\widehat{0}$ & $\begin{array}{l}2.500 \\
3.800\end{array}$ & $36.3 ; 36.1$ \\
\hline 9 & $\begin{array}{l}\text { Subklinik } \\
\text { gebelik } \\
\text { toksemisi }\end{array}$ & 3. & 145 & $\begin{array}{c}16 \mathrm{mg} \\
\text { Deksametazon }\end{array}$ & 40 & 2 & q; $q$ & $\begin{array}{l}2.600 \\
2.800\end{array}$ & $36.0 ; 35.9$ \\
\hline 10 & $\begin{array}{l}\text { Subklinik } \\
\text { gebelik } \\
\text { toksemisi }\end{array}$ & 3. & 143 & $\begin{array}{c}16 \mathrm{mg} \\
\text { Deksametazon }\end{array}$ & 44 & 3 & $\underset{\substack{+i}}{\lambda}$ & $\begin{array}{l}2.300 \\
2.700 \\
2.500\end{array}$ & $\begin{array}{c}36.1 ; 36.3 \\
36.1\end{array}$ \\
\hline 11 & $\begin{array}{l}\text { Subklinik } \\
\text { gebelik } \\
\text { toksemisi }\end{array}$ & 3. & 140 & $\begin{array}{c}16 \mathrm{mg} \\
\text { Deksametazon } \\
\text { tekrarlı }\end{array}$ & 30 & 2 & $+; \hat{0}$ & $\begin{array}{l}2.100 \\
2.750\end{array}$ & $38.1 ; 37.5$ \\
\hline 12 & $\begin{array}{l}\text { Subklinik } \\
\text { gebelik } \\
\text { toksemisi }\end{array}$ & 3. & 145 & $\begin{array}{c}16 \mathrm{mg} \\
\text { Deksametazon }\end{array}$ & 46 & 1 & $\delta$ & 3.700 & 36.5 \\
\hline 13 & $\begin{array}{l}\text { Subklinik } \\
\text { gebelik } \\
\text { toksemisi }\end{array}$ & 3. & 145 & $\begin{array}{c}16 \mathrm{mg} \\
\text { Deksametazon }\end{array}$ & 47 & 1 & q & 3.300 & 36.0 \\
\hline 14 & $\begin{array}{l}\text { Subklinik } \\
\text { gebelik } \\
\text { toksemisi }\end{array}$ & 3. & 144 & $\begin{array}{c}16 \mathrm{mg} \\
\text { Deksametazon }\end{array}$ & 47 & 1 & $\widehat{\partial}$ & 2.950 & 37.1 \\
\hline 15 & $\begin{array}{c}\text { Gebelik } \\
\text { toksemisi }\end{array}$ & 2. & 147 & 10 mg Dinoprost & 33,5 & 1 & 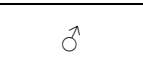 & 3.500 & 37.2 \\
\hline 16 & $\begin{array}{c}\text { Gebelik } \\
\text { toksemisi }\end{array}$ & 2. & Son hafta & $\begin{array}{c}16 \mathrm{mg} \\
\text { Deksametazon }\end{array}$ & - & 1 & q & 2.300 & - \\
\hline 17 & $\begin{array}{c}\text { Gebelik } \\
\text { toksemisi }\end{array}$ & 2. & 147 & $\begin{array}{c}16 \mathrm{mg} \\
\text { Deksametazon }\end{array}$ & 32 & 2 & 웅 & $\begin{array}{l}2.800 \\
3.150\end{array}$ & $36.1 ; 36.9$ \\
\hline
\end{tabular}




\section{Tartışma}

Evcil hayvanlarda doğuma yakın dönemde gözlenen hidroallantois, hidroamnion, fötal mumifikasyon, fötal membranların hidropsu, hernia, prepubic tendo rupturu, abdominal travma, keçilerin caprine artritis ensafilits sendromu, gebelik toksemisi, solunum problemleri (respiratuar distres) ve uzayan gebelik gibi patolojik durumlarda doğum indüksiyonu uygulanmaktadır (Fthenakis ve ark., 2012; Ingoldby ve Jackson, 2001; Jackson, 2004; Purohit, 2010; Purohit, 2012; Zoller ve ark., 2015). Sunulan çalışmada koyun ve keçilerde karşılaşılan subklinik gebelik toksemisi, gebelik toksemisi, abdominal travma ve respiratorik distress problemleri nedeniyle doğum indüksiyonuna başvuruldu.

Koyunlarda deksametazon, flumetazon, betametazon ya da kortizol asetat gibi kortikosteroidler yaygın olarak tercih edilmektedir (Zoller ve ark., 2015). Farklı dozlarda (1.5-25 mg arası değişmekte) deksametazon kullanılarak doğumun uyarıldığı pek çok çalışma bulunmaktadır (Harrison, 1982; Kastelic ve ark., 1996; Tsiligianni ve ark., 2008). Doğuma birkaç gün kala düşük dozlarda (1.5 mg, im.) yapılan kortikosteroid uygulamaları başarılı sonuçlar verse de (Tsigliannis ve ark., 2008), koyunlarda doğum indüksiyonu için total $16 \mathrm{mg}$ deksametazon'un kullanılması tavsiye edilmektedir (Ingoldby ve Jackson, 2001). Keçilerde ise deksametazon, misopristol, aglepriston ve bazı medikal preparatlar ile doğumun uyarıldığı bilinse de genellikle 5-10 mg dinoprost'un doğum indüksiyonu için yeterli olduğu bildirilmiştir (Purohit ve ark., 2012). Çalışmamızda doğum indüksiyonu amacıyla rutinde önerilen dozlar olan koyunlar için $16 \mathrm{mg}$ deksametazon ve keçiler için $10 \mathrm{mg}$ dinoprost kullanıldı. Olgu 3 ve $11^{\prime}$ de gebeliğin 140 . gününden önce yapılan deksametazon uygulamalarının hızlı yanıt vermemesi ve de indüksiyon doğum arası sürenin çok geniş aralıklara yayılması sebebiyle Zoller ve ark. (2015)'ın önerisi dikkate alınarak $16 \mathrm{mg}$ deksametazon 12 saat aralıklar ile tekrarlayan dozlar halinde uygulandı.

Kullanılacak ilaç anne ya da yavruda yan etki oluşturmamalı, doğumu kesinlikle başlatmalı ve kolay uygulanabilmelidir (Silver, 1990). Gebelik toksemisinin ileri evresinde yüksek doz ve tekrarlı deksametazon uygulamaları protein katabolizmasında artış meydana getirerek üremiye neden olmaktadır (Purohit ve ark., 2012). Ayrıca doğuma yakın zamanda yapılmayan doğum indüksiyonu sonucu doğum gerçekleşmeyebilir, servikal spazm gözlenebilir, postpartum retensiyo sekundinarum şekillenebilir, laktasyon başlamayabilir, yavru annesini emmeyebilir ve kolostrum kalitesi de düşebilir (Ingoldby ve Jackson,
2001; Taşal ve Şendağ, 2012; Zoller ve ark., 2015). Bundan dolayı doğum indüksiyonu uygulanmadan önce olgularda klinik ve transrektal ultrasonografi ile gebelik muayenesi yapılarak gebeliğin doğuma yakın olduğunun tespiti yapıldı. Yine doğum indüksiyonu sonrası olası yaşanabilecek problemlerin önüne geçmek için doğum gerçekleşene kadar ve postpartum süreçte koyun ve keçilerle birlikte doğan yavrular yakından takip edildi. Ayrıca belli aralıklarla koyun ve keçilerin genel muayenesi, idrar muayenesi, ultrasonografik muayene ile yavru canlılıklarının teyidi, vaginal muayene ile serviksin açıklığının kontrolü ve imkan dahilinde bireysel glukoz cihazı ile kan glukoz seviye ölçümleri ve mikroskobik total lökosit sayımları gerçekleştirildi. Olgu 16'nın (koyun) genel durumunda fark edilen kötüleşme nedeniyle sezaryen operasyonu yapıldı. Ayrıca olgu 7'de (keçi) fötal maldispozisyona bağlı güç doğum şekillendiği için doğuma elle müdahale edildi.

Deksametazon'un $16 \mathrm{mg}$ dozda 141. gebelik gününde uygulanmasının ardından 49.0 \pm 2.18 saat sonra (Shevah, 1974), 140. gebelik gününde uygulanmasının ardından ise 51 saat sonra doğumların gerçekleştiği bildirilmiştir (Kastelic ve ark., 1996). Deksametazon'un 138. gebelik gününde $16 \mathrm{mg}$ dozda uygulanmasını takiben 98.66 \pm 31.55 saatte doğumlar meydana gelmiştir ancak doğumların gerçekleştiği saat geniş aralıklara yayılmıştır (Salci ve ark., 2018). Ile de France ırkı koyunlara deksametazon 144. gebelik gününde 4 ve $16 \mathrm{mg}$ dozda uygulandığında sırasıyla $80.62 \pm 44.04$ ve $45.04 \pm 12.38$ saatlerde doğumun uyarıldığı bildirilmektedir (Bosc, 1972). Sunulan çalışmada gebeliği $144 \pm 2.92$ gün olan koyunlara uygulanan 16 mg deksametazon enjeksiyonu sonrası koyunlarda $36.1 \pm 10.32$ (20-47) saat içerisinde doğumlar gerçekleşti. Doğum, sadece doğumuna 1-2 gün kalan vakalarda 20 saat içerisinde şekillendi. Diğerlerinde 31.5 saatten önce gerçekleşmedi. Gebelik süresi 140. günden önce olan koyunlarda 12 saat aralıklı tekrarlayan dozlar halinde uygulanan dekzametazon sonrası doğumun gerçekleşme süresi sırasıyla olgu 11 ve 2'de 30 ve 34 . saatti. Bir koyun (olgu 17: 32. saat) hariç diğerlerinde doğumlar 40. saat ve üzerinde şekillendi.

Keçilerde 10 mg PGF2 $\alpha$ analoğunun 141-142. gebelik günlerinde uygulanması sonrası $36.17 \pm 2.80$ saatte (Arsoy Başaran ve ark., 1996) ve 142. gebelik gününde uygulanması sonrasında ise 34.8 saatte (Alan ve Taşal, 2002) doğumların başladığı bildirilmiştir. Farklı dozlarda 140-142. gebelik gününde 15 mg PGF2 $\alpha$ enjeksiyonu sonrası 42-76 saat içerisinde (Bosu ve ark., 1979) ve 144. gebelik gününde 2.5-5 mg PGF2 $\alpha$ enjeksiyonunu takiben $43 \pm 11.8$ ve $35 \pm 8.6$. saatlerde (Bretzlaff ve Ott, 1983) doğumların gerçekleştiği de rapor edilmiştir. 
Doğuma daha yakın dönemlerde ise; gebeliğin 146148. gebelik gününde $0.5 \mathrm{mg}$ dozda bir prostaglandin analoğu olan fenoprostalane'nin subkutan yolla enjeksiyonunu takiben $31.6 \pm 0.83$. saatte doğumların gerçekleştiği bildirilmiştir (Haibel ve Hull, 1988). Gebeliğin 145. gününde bir başka prostaglandin analoğu olan $75 \mu$ g cloprostenol, 7.5 $\mathrm{mg}$ ve $3.75 \mathrm{mg}$ luprostiol enjeksiyonunu takiben 3335 saat içerisinde doğumların meydana geldiği görülmüştür. Sunulan çalışmada gebelik günü 145.2 \pm 1.41 (144-147) olan keçilerde 34.41 \pm 2.95 (31.5-40) saat sonra $10 \mathrm{mg}$ dinoprost ile uyarılmış keçilerden biri hariç (fötal malpozisyon nedenli doğumu 40 saat sonra elle müdahale ile gerçekleşen) doğumlar yaklaşık aynı zaman diliminde sonuçlanmıştır. Ancak gebelik günü daha ileri olmasına rağmen Arsoy Başaran ve ark. (1996) ile Alan ve Taşal'ın (2002) verileri ile yaklaşık aynı saatlerde doğumlar gerçekleşmiştir.

Başarılı bir doğum indüksiyonunda yavru canlılı̆ı etkilenmez (Silver, 1990) ancak koyunlarda doğum indüksiyonu, tahmini doğum zamanına yakın yapılmazsa (133. günden önce doğan kuzuların ölüm oranı \%70) premature doğacak olan yavrunun akciğerinin gelişememiş olması, vücut sıcaklığını muhafaza edememesi, anneyi emememe ya da kolostrumu yeterli sindirememe gibi problemlerin ortaya çıkmasına neden olur (Ingoldby ve Jackson, 2001; Silver, 1990). Şekillenecek hipoksi, asidoz, hipoglisemi, hipotermi ya da immun yetersizlik sonucu yavrunun kaybı söz konusu olabilmektedir (Silver, 1990). Gebeliğin 142. gününde 6-12 mg deksametazon'un im yolla tek enjeksiyonu ile güç doğum olmaksızın ve yavru canlılığı etkilenmeden doğum uyarılabilmektedir (Webster ve Haresign, 1981). Başka bir çalışmada, gebeliğin 145. gününde $15 \mathrm{mg}$ deksametazon uygulamasında yavru doğum ağırlığının 3.8-4.2 kg, canlı doğum oranının \%92.893.3 ve 1 aylık yaştaki yaşama oranlarının ise \%66.671.4 olduğu bildirilmiştir (Bailos ve ark., 2008). Skinner ve ark. (1970) 138-140. günler arasında yapılan doğum indüksiyonu sonucu yeni doğan vücut ağırlıkları arasındaki anlamlı fark olduğunu, deney grubu ile kontrol grubu yavrularının büyüme oranları değerlendirildiğinde anlamlı bir farklılık olmadığını bildirmişlerdir. Batista ve ark. (2009) canlı yavru doğum oranını doğumun uyarıldığı grupta \%93.9, kontrol grubunda ise \%83.9 olarak bildirmişlerdir. Doğum indüksiyonu sonrası koyun ve keçilerde yavru doğum ağırlıklarının deney gruplarında daha az olduğu tespit edilmiştir (Arsoy Başaran ve ark., 1996; Rommereim ve Slyter, 1981; Sanchez-Aparicio ve ark., 2009; Sir ve Bartlewski, 2010). Bu farklılığın indüksiyonun yapıldığı günle ilişkili olduğu, doğuma yakın dönemde yapılan doğum indüksiyonunda yavru ağırlık farklılıklarının gözlenmediği (Batista ve ark., 2009), doğuma yakın olmayan dönemde yapılan doğum indüksiyonunun ise yavru ağırlığını etkilediği bildirilmiştir (Sir ve Bartlewski, 2010). Sunulan çalışmada, koyunlardan 18 adet kuzu (10 erkek ve 8 dişi) elde edildi ve sadece 1 kuzu ölü doğdu. Keçilerden de 6 erkek, 3 dişi olmak üzere toplam 9 adet oğlak doğdu. Kuzular ile oğlaklar arasında vücut sıcaklıkları ve doğum ağırlıkları bakımından anlamlı bir fark bulunmadı $(P<0.05)$.

Sonuç olarak, koyun ve keçilerde uygulanılan rutin doğum indüksiyon metotları annenin genel durumunun iyi ve olgunun acil olmadığı durumlarda tercih edilebilir. Koyun ve keçilerde doğum indüksiyonuna alınan yanıt olumludur ancak olgunun aciliyeti söz konusu olup gebeliğin bir an evvel sonlandırılması gerekiyorsa doğum indüksiyonu yerine sezaryen operasyonu yapılması daha uygun bir yaklaşım olacaktır.

\section{Kaynaklar}

Alan M, Taşal I, 2002: Efficacy of prostaglandin $F_{2 \alpha}$ and misoprostol in the induction of parturition in goats. Vet Rec, 150, 788-789.

Arsoy Başaran D, Karakaya A, Bilgiç N, Aşkın Y, 1997: Effective doses of prostaglandin F2 alpha for induction of parturition in Angora goats. Turk J Vet Anim Sci, 21, 13-16.

Bailos SA, Kassim MS, Al-Oramary RAS, 2008: Induction of parturition in ewes (local breeds) and subsequent survival of neonates. Egypt J Sheep Goat Sci, 3(2), 65-70.

Batista M, Nino T, Alamo D, Gonzalez F, Santana M, Rodriguez N, Cabrera F, Gracia A, 2009: Use of luprostiol and cloprostenol for induction of parturition in pregnant goats. Reprod Domes Anim, 44, 83-87.

Batista M, Reyes R, Santana M, Alamo D, Vilar J, Gonzalez F, Cabrera F, Gracia A, 2011: Induction of parturition with aglepristone in the majorera goat. Reprod Dom Anim, 46, 882-888.

Bosc MJ, 1972: The induction and synchronization of lambing with the aid of dexamethasone. J Reprod Fertil, 28(3), 347-57.

Bosu WTK, Garibay JAS, Baker CAV, 1979. Pheriperal plasma levels of progesterone in pregnant goats and in pregnant goats treated with prostaglandin $\mathrm{F} 2 \alpha$. Theriogenology, 11(2), 131-148.

Bretzlaff KN, Ott RS, 1983: Doses of prostaglandin F2 alpha effective for induction of parturition in goats. Theriogenology, 19(6), 849-853.

Currie WB, Thorburn GD, 1973: Induction of premature parturition in goats by prostaglandin $F_{2 \alpha}$ administered into the uterine vein. Prostaglandins, 4(2), 201-214.

Fthenakis GC, Arsenos G, Brozos C, Fragkou IA, Giadinis ND, Giannenas I, Mavrogianni VS, Papadopoulos E, Valasi I, 2012: Health management of ewes during pregnancy. Anim Reprod Sci, 130, 198-212. 
Gelegen K, 2013: Postdate gebelik nedeni ile doğum indüksiyonu uygulanan düşük servikal bishop skoru olan gebelerde indüksiyon başarısını etkileyen faktörler. Çukurova Üniversitesi Tıp Fakültesi Kadın Hastalıkları ve Doğum Anabilim Dalı, Uzmanlık Tezi, Adana, Türkiye.

Haibel GK, Hull BL, 1988: Induction of parturition in goats with fenprostalane. Theriogenology, 30(5), 901-903.

Harrison FA, 1982: Dexamethasone-induced parturition in sheep. British Vet J, 138, 402-408.

Ingoldby L, Jackson $P, 2001$ : Induction of parturition in sheep. In Practice, 23, 228-231.

Jackson PGG, 2004: Handbook of Veterinary Obstetrics. Saunders, UK, pp. 245.

Karademir Ö, 2005: Bishop skorunun başarılı doğum indüksiyonunun öngörülmesindeki değeri. Bakırköy Doğumevi Kadın ve Çocuk Hastalıkları Eğitim Hastanesi, Uzmanlık Tezi, İstanbul, Türkiye.

Kastelic JP, Cook RB, McMahon LR, McAllister TA, McClelland LA, Cheng KJ, 1996: Induction of Parturition in Ewes with Deksametazon or Deksametazon and Cloprostenol. Can Vet J, 37, 101102.

Lima MS, Pascoal RA, Stilwell GT, Hjerpe CA, 2012: Clinical findings, blood chemistry values, and epidemiologic data from dairy goats with pregnancy toxemia. Bovine Pract, 46(2), 102-110.

Purohit G, 2010: Parturition in domestic animals: a review. WebmedCentral Reproduction, WMC00748, 1(10), 1-18.

Purohit G, Shekher C, Kumar P, Solanki K, 2012: Induced termination of pregnancy in domestic farm animals. Iran J Appl Anim Sci, 2(1), 1-12.

Rommereim DN, Slyter AL, 1981: Effect of day of gestation on induction of lambing with flumethasone. J Anim Sci, 53(3), 564-566.

Salci ESO, Demirbilek Kahya S, Gunes N, Goncagul G, Uzabaci E, Carli T, Seyrek Intas K, 2018: Endocrinological and immunological comparision of different parturition induction methods in ewes. Tierarztl Prax Ausg G Grosstiere Nutztiere, 46(1), 22 28.

Sanchez-Aparicio P, Mota-Rojas D, Trujillo-Ortega ME, Zarco-Quintero LA, Becerril-Herrera $M$, AlonsoSpilsbury M, Alfaro-Rodriguez A, 2009: Effect of prostaglandins for inducing birth on weight, vitality and physiological responce in newborn pigs. J Appl Anim Res, 36, 113-118.

Taşal i ve Şendağ S, 2012: Doğum. In: “Çiftlik Hayvanlarında Doğum ve Jinekoloji”, Ed; Semacan A, Kaymaz M, Fındık $M$, Rişvanlı $A$, Köker $A$, Bölüm 7, Medipres, Malatya, Türkiye, s. 187-192.

Shevah Y, 1974: A note on the use of deksametazon for inducement of parturition of Finn $x$ Dorset ewes. Anim Product, 18(1), 89-92.

Silver M, 1990: Prenatal maturation, the timing of birth and how it may be regulated in domestic animals. Expert Phy, 75, 285-307.

Sir C, Bartlewski PM, 2010: Analyses of parenteral and seasonal influences on the synchrony of deksametazon-induced lambing and lamb characteristics. Livest Sci, 131, 119-124.
Skinner JD, Jöchle W, Nel JW, 1970: Induction of parturition in Karakul and crossbred ewes with flumethasone. Agroanimalia, 2, 99-100.

Tsiligianni T, Ntovolou E, Amiridis GS, 2008: Synchronisation of lambing with low doses of deksametazon in Chios Ewes-short communication. Acta Vet Hung, 56(3), 393-397.

Webster GM, Haresign W, 1981: A note on the use of dexametasone to induce parturition in the ewe. Anim Reprod, 32(3), 341-344.

Zoller DK, Vassiliadis PM, Voigt K, Sauter-Louis C, Zerbe $\mathrm{H}$, 2015: Two treatment protocols for induction of preterm parturition in ewes- evaluation of the effects on lung maturation and lamb survival. Small Rumin Res, 124, 112-119.

*Yazışma Adresi: E. Sinem ÖZDEMIR SALCI

Uludağ Üniversitesi, Veteriner Fakültesi, Doğum ve Jinekoloji Anabilim Dalı, Görükle Kampüsü, 16059, Bursa, Türkiye

E-mail: ssalci@uludag.edu.tr 